This item was submitted to Loughborough's Research Repository by the author.

Items in Figshare are protected by copyright, with all rights reserved, unless otherwise indicated.

\title{
Mapping the conceptual design activity of interdisciplinary teams
}

PLEASE CITE THE PUBLISHED VERSION

PUBLISHER

(C) Elsevier

VERSION

AM (Accepted Manuscript)

LICENCE

CC BY-NC-ND 4.0

REPOSITORY RECORD

Austin, Simon A., John Steele, Sebastian Macmillan, Paul Kirby, and Robin Spence. 2019. "Mapping the Conceptual Design Activity of Interdisciplinary Teams”. figshare. https://hdl.handle.net/2134/4225. 
This item was submitted to Loughborough's Institutional Repository (https://dspace.lboro.ac.uk/) by the author and is made available under the following Creative Commons Licence conditions.

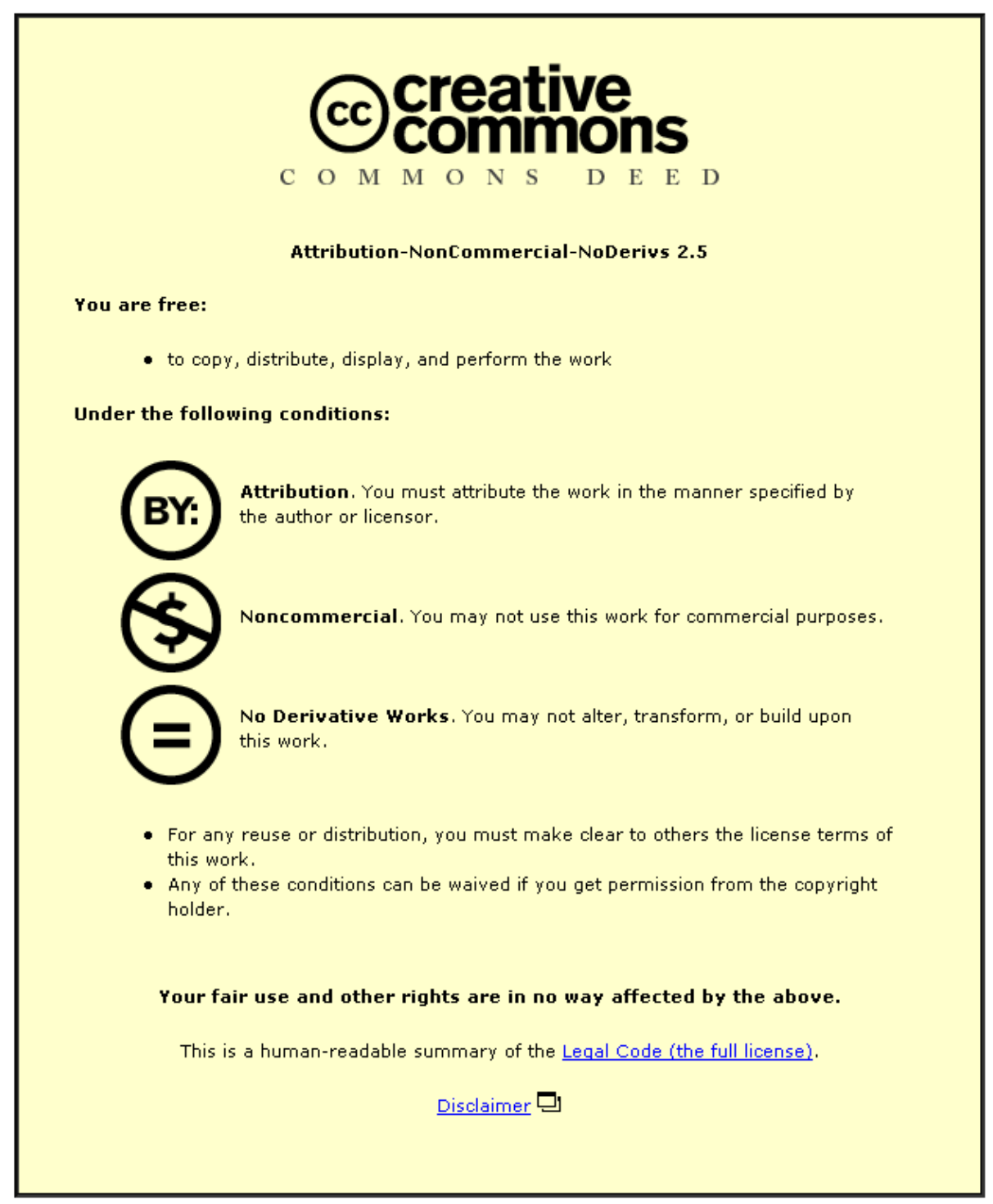

For the full text of this licence, please go to: http://creativecommons.org/licenses/by-nc-nd/2.5/ 


\title{
Mapping the conceptual design activity of interdisciplinary teams
}

\author{
Simon Austin ${ }^{1}$, John Steele ${ }^{2}$, Sebastian Macmillan ${ }^{2}$, Paul Kirby ${ }^{2}$, Robin Spence $^{2}$ \\ (1) Department of Civil and Building Engineering, Loughborough University, Loughborough, \\ Leicestershire, LE11 3TU. \\ (2) The Martin Centre for Architectural and Urban Studies, Department of Architecture, University of \\ Cambridge, 6 Chaucer Road, Cambridge, CB2 2EB, UK
}

\section{Keywords}

Evaluation, conceptual design, design process, interdisciplinary, teamwork.

\section{Synopsis}

The conceptual design phase of any project is, by its very nature, a vibrant, creative and dynamic period. It can also be disorganised with much backtracking accompanying the exchange of information between design team members. The transfer of information, ideas and opinion is critical to the development of concepts and as such, rather than being recognised as merely a component of conceptual design activity, it needs to be understood and, ultimately, managed. This paper describes an experimental workshop involving fifteen design professionals in which conceptual design activity was tracked, and subsequently mapped, in order to test and validate a tentative design framework (phase and activity model). The nature of the design progression of the various teams is captured and analysed, allowing a number of conclusions to be drawn regarding both the iterative nature of this phase of design and how teams of professionals actually design together. 


\section{Introduction}

\subsection{An overview of the research domain}

Many writers in the field of design research have produced maps and procedures for negotiating what has become commonly known as the design process. Markus ${ }^{1}$ and Maver ${ }^{2}$, French ${ }^{3}$, Archer ${ }^{4}$, Pugh and Morley ${ }^{5}$, Pahl and Beitz ${ }^{6}$ and Cross ${ }^{7}$ are just some of the many writers, from across the architectural and engineering design domain, who have attempted to generate standardised design procedures. Yet it is disturbing that, although the work of these many writers has been utilised with varying degrees of success in a number of engineering domains, the construction industry has shown little interest in defining a procedure aimed at improving the efficiency of their design activity. This is not to say that the building industry has failed to benefit from the implementation of standardised procedure altogether, as the construction phase of any building project is planned thoroughly in a bid to improve efficiency and reduce time spans. So why has there been little transfer of this philosophy to the activity of design?

The lack of appreciation of the rewards that can be gained from planning design activity seems to owe much to the fact that design and construction are often perceived as being mutually exclusive activities. This is to say that the activity of designing was undertaken by a discrete group of individuals that would hand over their work to the construction engineers, at which point their input to the project would end. Thus, the activities of design and construction became segregated. This resulted in the common misconception that design could be managed without the help of specific planning and management 
tools, whilst in construction there were clearer and more easily realisable benefits from improved planning ${ }^{8}$.

In today's lean construction environment this myth is being dispelled and it has become generally recognised that efficiency and client satisfaction can be improved if design activity is planned and managed. Thus, methods such as the Analytical Design Planning Technique (ADePT) have been developed, which have focused to date on the development of models of the detailed design phase ${ }^{9}$ and are currently being applied within the construction industry. Through the collaborative research work of a number of academic institutions, construction organisations and clients, attempts have been made to closely integrate all the phases involved in bringing a building to a customer. This research has resulted in the production of several standardised process maps, the most notable of which are the BAA Project Process ${ }^{10}$ and the Process Protocol ${ }^{11}$, which seem to be converging toward a similar format. However, at present the RIBA Plan of Work for Design Team Operation ${ }^{12}$, which was developed some 30 years ago, remains the most widely used model of building design, although it is currently under revision in the light of these latest developments.

\section{$1.2 \quad$ Research focus}

The areas of building industry research documented above have focused on improving understanding of the entire design process but investigations have also been undertaken which concentrate on the individual stages of the process. It could be argued that these more detailed analyses are of more direct relevance to the industry as they de-mystify the 
intricacies of design activity at a deeper and more detailed level. More over, it is only by understanding the activities involved within the individual stages of design that the interfaces between stages of work can be understood and subsequently managed.

The existing systematic design procedures advocated by the engineering researchers have rarely been subjected to any realistic evaluation in practice $13,14,15$. Nevertheless, it is still claimed that their use will lead to better quality artefacts and/or shorter time to design completion ${ }^{13}$. In the few instances that the earlier models have been tested on live projects their phases account for only a fraction of the actual activity that occurs ${ }^{14,15}$. For example, when the systematic design model of Pahl and Beitz ${ }^{6}$ was subjected to a detailed investigation in a live design project in practice, the activities that were accounted for by the model made up only $47 \%$ of the design team work ${ }^{14}$. The more recently developed models of the design process, such as those generated using ADePT, have proven significantly more robust, with models of the detailed design phase proving to be $90 \%$ generic in applications to date ${ }^{8}$. Testing of Hubka's ${ }^{16}$ model of engineering design failed to validate claims that design cycle time or artefact quality were positively affected by the use of systematic procedure ${ }^{13}$.

The Mapping the design process during the conceptual phase of building projects (MDP) research project, currently being undertaken at the University of Cambridge, with support from the Department of Civil and Building Engineering, Loughborough University, is investigating the most vibrant but disorganised of the phases, namely conceptual design. This paper describes the testing of a preliminary conceptual design framework (phase and 
activity model) that has been developed over the course of this project. An experimental session was held in a bid to both verify the framework structure and ensure that its components were subjected to rigorous testing in a live design environment. It also allowed the research team to monitor and subsequently analyse how design professionals undertake collaborative design activity.

\subsection{Development of the conceptual design framework}

An extensive literature search, which involved the collection, and subsequent analysis, of the existing design process models, enabled a direct comparison to be made between the phases outlined in these various descriptions, the details of which are provided elsewhere 17. In addition to this, two further sources of information were added. First, several case study investigations, involving systematic interviewing and archive analysis, were undertaken to gain an understanding of the activities and phases performed over the conceptual phase of various building industry projects. Second, a previous workshop that had been held, the form of which mirrors that of the workshop described here, enabled the phases of design progression over a concentrated period to be recorded and analysed 18. The subsequent combination of these three sources of information allowed a preliminary conceptual design framework (Figure 1) to be developed for testing ${ }^{19}$.

\section{Overview of the workshop}

\subsection{Workshop description}

The workshop was held over a two-day period and involved delegates from a number of building design industry organisations, representing the industrial collaborators from the 
MDP research project. The workshop had three major aims: to test the applicability and validity of a preliminary model of the conceptual design phase; to provide an additional opportunity to monitor interdisciplinary design teams in practice; and to test a number of 'Team Thinking Tools’ that had been identified during the course of the research.

The session involved fifteen design professionals in total, with each of the collaborating organisations being represented. The fifteen delegates were divided into three teams, each team comprising five designers, with each organisation being represented once in every team. This ensured that each team had a full compliment of the relevant building design disciplines, namely architects, building services engineers, civil/structural engineers. This also reflected the way in which teams are newly formed in practice.

Two of the teams were designated as test groups and the third as the control group. The two test groups were provided with a copy of the preliminary conceptual design framework (shown in figure 1) and tutored on its terminology and structure. 


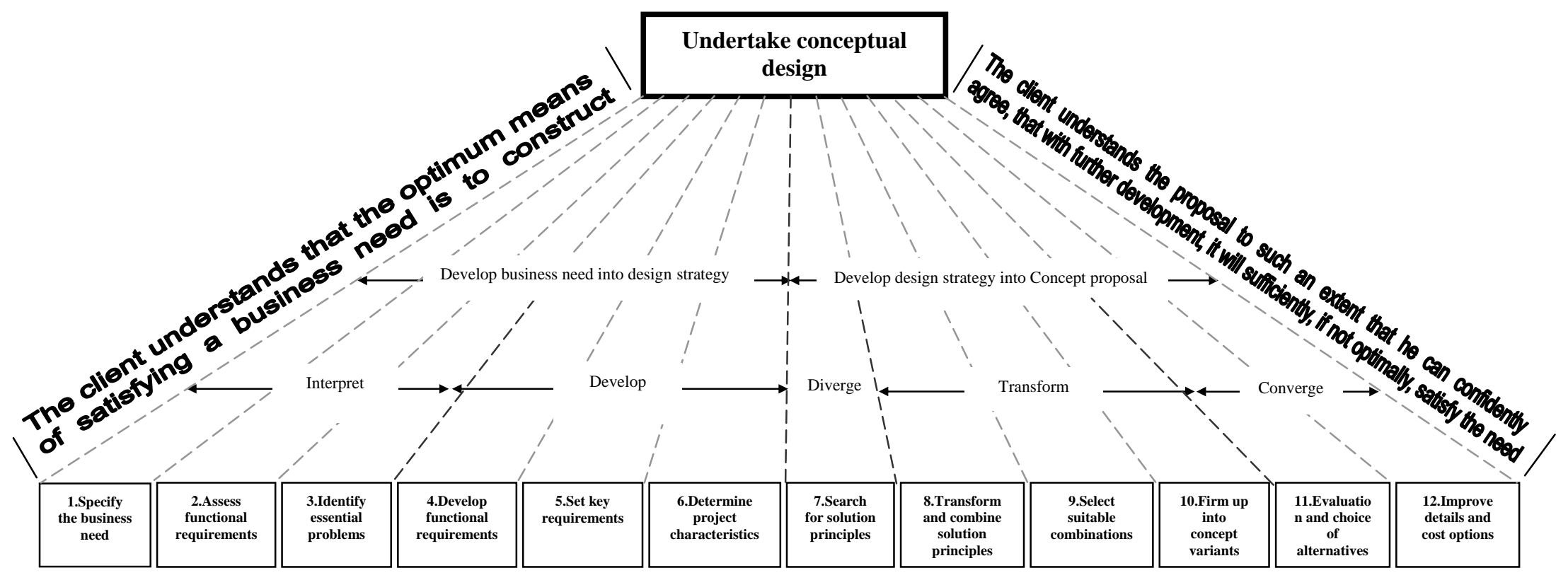

Figure 1 The preliminary conceptual design framework 
One team was given the option to follow it while the other team was asked to follow it. The two teams were then introduced to the brief and told to begin the exercise. The third team was asked to solve the design problem without the framework model.

Each team was provided with a booklet of Team Thinking Tools (design techniques or methods such as brainstorming and mind mapping) which they were asked to use during the exercise. A brief presentation of these tools was provided, which gave the delegates an insight into how to apply and use the tools and which particular periods of design each tool was developed to assist. Details of this component of the investigation are provided elsewhere ${ }^{20}$.

\subsection{Workshop format}

Each team was asked to design an adaptable and flexible modular window system that could be used to reclad existing office buildings. The brief stated that the system should be a manufactured product, available virtually from stock, and should enhance the environmental performance of the building. A number of design requirements and parameters were outlined, which provided the teams with some initial constraints. A halfhour presentation was given to introduce the cladding exercise, which comprised a wideranging and well illustrated review of the function and history of the window. This presentation drew examples of many types and forms of window and introduced a number of passive environmental conditioning strategies such as the use of Brise-soleil and low emissivity glazing. 
Upon completion of the exercise, the individual team members were asked to complete questionnaires. Teams $\mathrm{A}$ and $\mathrm{B}$ completed questionnaires relating to the design framework model, the respective team performance, and the usefulness of the design techniques. Team C completed the latter two only.

During actual design activity, a member of each team recorded the phases of design as they were being undertaken and the design activities performed. This recording was undertaken at five-minute intervals throughout the duration of the exercise. To verify and support this self-assessment, members of the research group monitored each team and made notes of both the time and activities being observed. This provided additional information regarding the design activity and also acted as a means of verifying the selfassessment records. The information provided by these questionnaires, combined with the observations made during the course of the design activity, allowed a number of preliminary findings to be drawn. Additionally, the data gathered during the session allowed patterns of each team's design progression to be generated.

Once finished, the respective concept proposals were presented in a 20-minute pin-up. Although it was not a pre-requisite, each team member presented a section of the proposal. Three independent experts critiqued the proposals and ranked them with respect to the ease of which they could be subsequently developed into workable solutions that satisfy the brief. 


\section{$3 \quad$ Workshop findings}

This particular design problem, although appearing to be relatively simple, has the advantage of requiring input from each of the design disciplines. Those teams that realise the need for integration of the disciplinary issues into simple systems tend to be most successful. Each of the teams produced appropriate concepts that they believed could be subsequently developed into working systems. However, the manner in which the teams worked and the nature of the proposals produced were quite different.

\subsection{Observation and team member perception}

\section{Team A}

Team A was given the option to use the framework as a guide to the design stages but were not encouraged to use it as a systematic procedure. The team spent 305 minutes designing over the course of the workshop. Figure 2 provides a detailed outline of the activities undertaken and the time spent within each activity and phase of the framework.

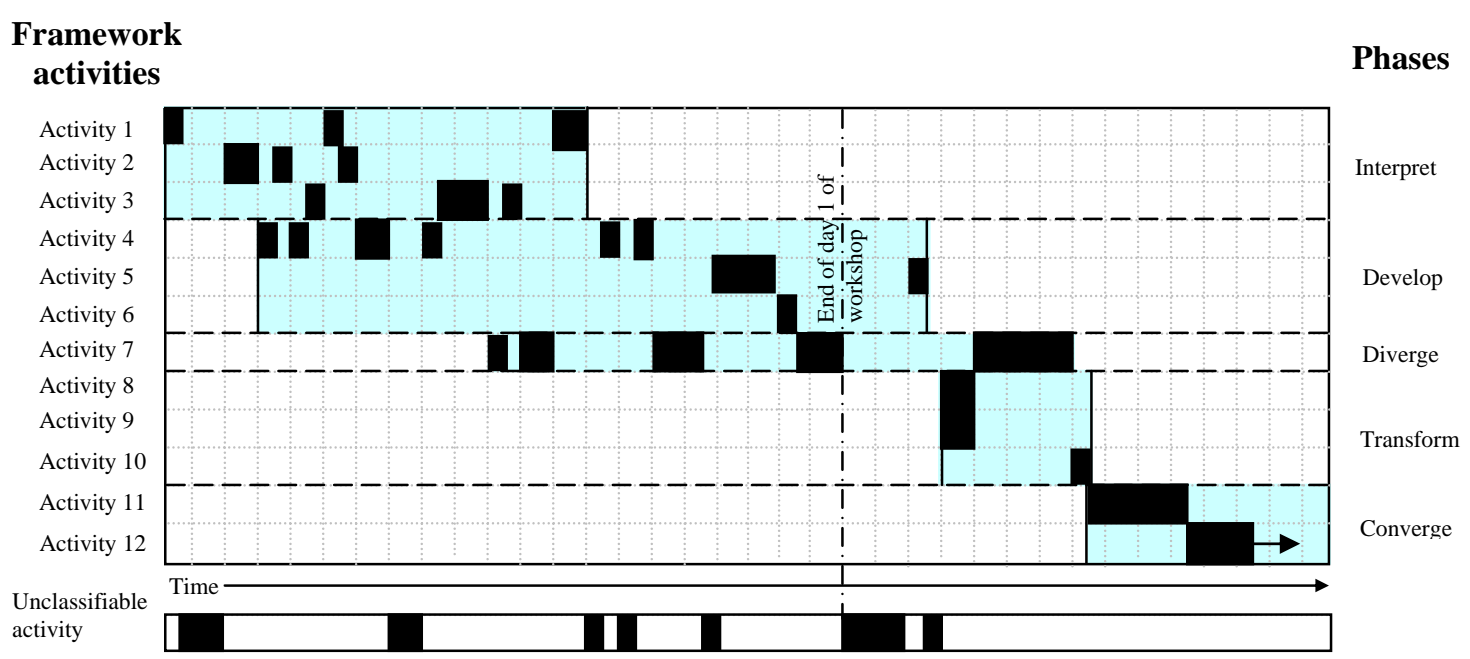

Figure 2 The design activity of team A 
Team A followed the design framework to some extent but jumped between activities. However, although the iteration was indiscriminate in manner, a noticeable sequential pattern is apparent which suggests that the framework has actually been followed, albeit fairly loosely. It is important to note that a reasonable period of design time, approximately 1 hour, could not be classified within the proposed framework.

Team A produced a 'kit of parts' solution to the problem, which comprised a number of interchangeable, standardised components from which a client could select the most applicable arrangement. The phrase 'kit of parts' not only describes the solution but also the way in which the team worked. The group did not interact well. Instead, each member looked at a different element of the problem, with these partial solutions being brought together at the end. There was little, if any, integration between the disciplines despite the fact that the disciplinary components were connected.

The team leader (who had assumed this role) appeared to guide the group through the design activity without agreeing this direction with the remainder of the team. It was commented that 'the design appeared to be a vehicle for the leaders enthusiasms'. Later, the leader commented that he had taken control because the team was too timid as a group, with no one being prepared to take the lead role. As such, the leader progressed through the activities without consulting the other team members.

This opportunistic design progression led to discontentment between members of the team, and resulted in a confrontational atmosphere and lack of cohesion between 
individuals. To this end the team in their own words 'sometimes lacked direction', with a 'split in focus of team members' and as a result, the team members 'grew frustrated'. One team member stated that the lack of common agreement on how to progress was the basis of the team's problems. Even though the team discussed the lack of cohesion felt by some of the design members at the start of the second day; no action was undertaken to address it. However, the dissatisfied team members felt that 'the design collaboration improved' to some extent, thus they bought back into the design progression. However, there were ‘still undercurrents of a lack of collaboration’ and as such, team members soon fell back into their disciplinary sub-teams as the work progressed. The divisions remained apparent throughout the exercise. It was also noted that there was a clash of personalities within the team; a factor that did not aid the situation.

Team members reported that the framework could guide the design process if the entire team would agree to follow it (findings would suggest that agreement on any procedure would improve team interaction, collaboration, and resultantly, team effectiveness). The early jumping between activities did not help the team, making the individual members frustrated. Interestingly, it was stated that because the framework was not followed in sufficient detail, being referred to after the fact, it was not used as it should have been e.g. as a guiding principal. Additionally, it was stated that 'someone needed to catch the process, as [the team] tended to jump around the process rather than use it as a [sequential] process'. Several team members agreed that concerns were not aired at an early enough time in the process to enable the team to make changes and remedy the situation. 


\section{Team B}

The members of Team B spent 250 minutes designing. The team members were encouraged to follow the framework's activities sequentially with a minimum of iteration (Figure 3).

After beginning the exercise by progressing sequentially through the activities, one member of team B undertook an opportunistic advance into generation of concepts (activity 7). The remainder of the members opposed this individual's transgression of the proposed use of the framework and after a brief discussion it was decided that the team should progress in unison. Thus, this step was disregarded during a subsequent analysis of activity dependency (as will be described in section 4.3). After reconvening at activity 1, team B followed the framework fairly rigidly for the remainder of the exercise. Again, it was noted that approximately $10 \%$ of design time, (30 minutes) could not be classified by the framework activities.

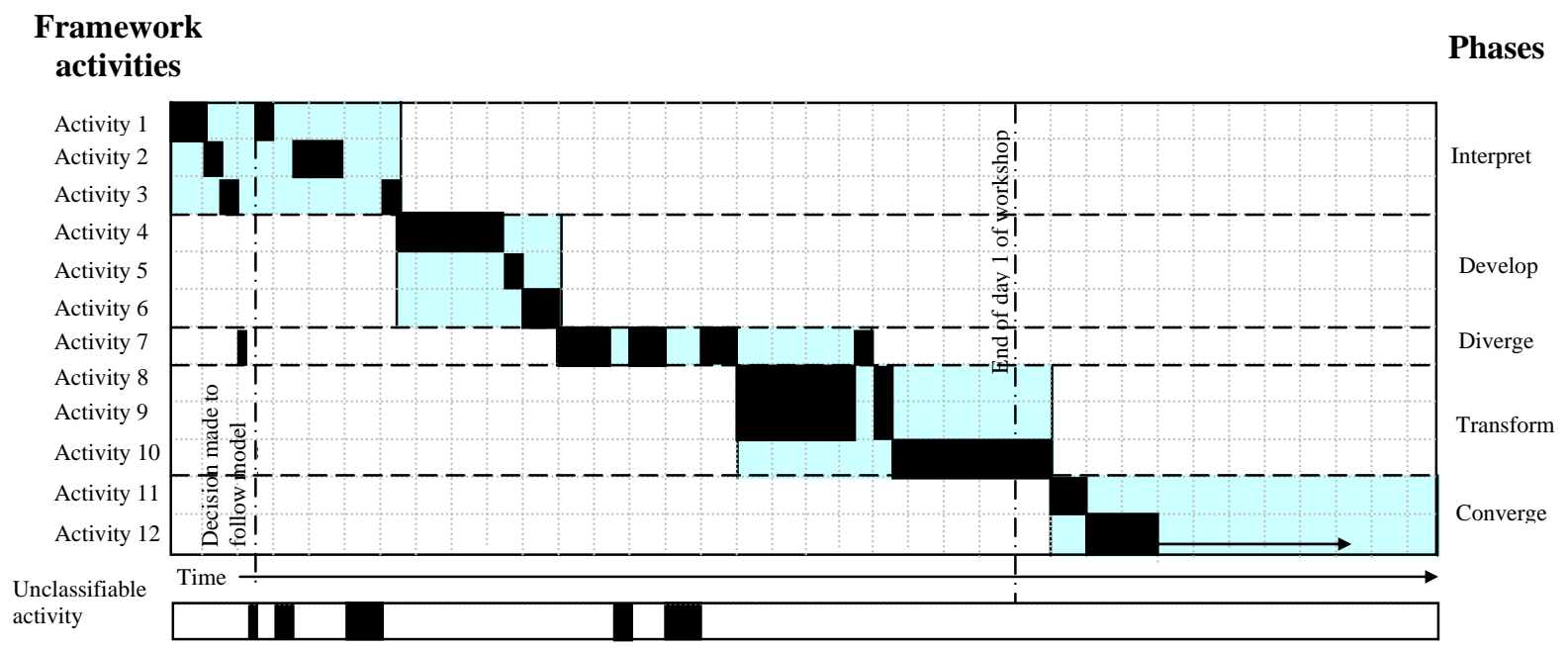

Figure 3

The design activity of team (B) 
The concept generated by team B was based around a clip-on spandrel of limited use in terms of either aesthetics or shading. The design concept was generally undeveloped, with the concept tending to re-create the type of environmental problem that it was attempting to remedy.

The crudity of the solution seemed to be the result of a mistaken belief that the problem was simple. Generally, a high level of cohesion was apparent within the group but, though the team interacted well throughout, the resulting concept was judged fairly poor by the expert assessors.

The team members discussed their roles in advance of the design activity and, with one exception, were happy about their positions, with individuals being flexible in their approach to forwarding ideas across the boundaries of the disciplines. The objector, whose background was in project management, felt that the leader had assumed sole responsibility for the position, and had not let the other team members become involved in progressing the design. However, on reflection, no other member of the team stated that they had wanted to 'lead' the design at any time before, during or after the exercise. In fact, one individual stated that 'the group worked together very well right from the start, but became even more organised as time went on'.

It was suggested that the team selection is a key factor in the success of design activity. One suggestion for getting the interaction element correct was to let the team members 
pick themselves. One team member felt that there was too much interest in details, rather than in ensuring that the strategy/concept was defined.

\section{Team C}

Team C, who had not been given a copy of the design framework, coincidentally undertook each of the activities that were outlined by the document. This acted as further validation of the proposed framework. However, the design activity was undertaken in a different fashion from the other teams (figure 4), although in a similar time period (245 minutes) to Team B.

Team $\mathrm{C}$ moved through the activities very quickly in a fairly rigid fashion to the point at which a number of alternatives needed to be evaluated. In attempting to evaluate these alternatives it became apparent that none was felt to satisfy fully the requirements of the brief and in consequence, the team came to an abrupt halt.

A member of the research team then interjected and facilitated the use of one of the team thinking tools. This resulted in the team jumping back a number of stages and recommencing their design activity from an earlier phase (see double iteration in figure 4). Again, a considerable amount of time (40 minutes) was not classifiable.

Although the team's concept design was not quantified fully, it was judged to be imaginative and to have recognised the areas of incompatibility between sub-elements of the problem. It was apparent that the team had differentiated between interconnected and 
unconnected characteristics. Thus, the solution was fairly simple, while still addressing the requirements of the brief.

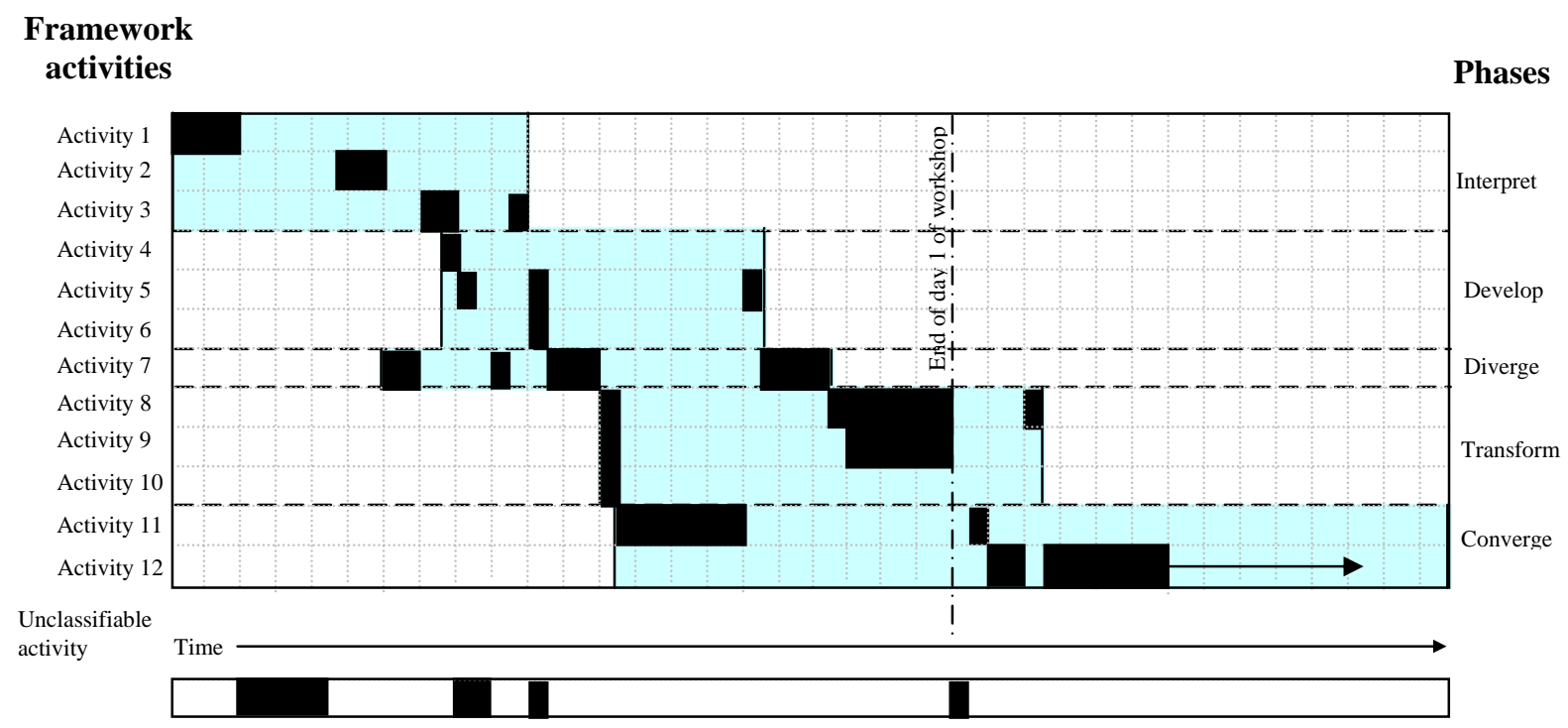

Figure 4 The design activity of team C

The team highlighted their frustration at not having any certain direction during the design exercise. The group attributed this to not having been given, nor defining for themselves, a process to follow prior to commencing the design activity. As such, they approached the design activity in an ad hoc manner; a factor that the team believed led to a 'general lack of direction' and caused frustration. Even so, the team generally followed the activities outlined in the conceptual framework that the other teams were given.

One team member stated that the team 'often lacked guidance and little process [was] used'. He felt that the team avoided confrontation and generally agreed on the way forward, but '[they] stumbled forward in design terms'. Additionally, it was felt that there was a need to capture and record ideas as they came; a lack of this combined with a lack 
of an agreed process caused frustration. However, despite some individuals having doubts about the potential contribution that they could provide in the early stages of the activity, a full team effort did occur later in the process.

Another team member held a similar view, stating that 'at the beginning of the exercise the team members did not really gel’. He felt that this initially caused different stances to be taken by individuals during the idea development stages. This individual suggested that the problem would have been overcome if they had had a process, either imposed or self generated, with which to harmonise their activity.

\section{Critique of the three schemes}

A critique was held at the end of the design period. Of the three teams, team $\mathrm{C}$ was adjudged to have produced the best proposal. This appeared to owe much to the team sharing the leadership, with each member tending to advise and then ask for comment, instead of simply dominating the flow of work. The negative aspect of this was the occasional lack of leadership, with no single member being willing to take the lead in times of dispute (the group was too polite to allow that to happen). The key to the success of the proposal seems to be that they had a wide knowledge base and were willing to listen to one another.

\subsection{Questionnaire responses}

The information gathered from the design framework and team performance questionnaires is shown below. A five point Likert scale was applied with 5 and 1 
representing the maximum positive and negative responses respectively and 3 as neutral. Figures 5 and 6 provide an overall team response to each question. The team responses have been plotted against one another to allow a comparison to be drawn.

\begin{tabular}{|l|l|l|}
\hline $\begin{array}{l}\text { How would you rate the design that the group has produced for } \\
\text { the task? }\end{array}$ & & \\
\hline Which number best describes the way the group took decisions? & &
\end{tabular}

Legend:

Team (A)

Team (C) - - - -

Figure 5 Team performance questionnaire responses by team

On average team B scored their performance higher than teams A and C and in all cases positively. Teams C and A rated themselves similarly to team B for their group member contribution and for the way their individual ideas had been included in the design sketches respectively. The latter rating undoubtedly owes much to the fact that team A generated a kit-of-parts solution, which included the ideas of all its members, rather than deciding to develop a single concept.

Only team A responded negatively to any of the questions - these related to group organisation and individual's satisfaction with the way the team used its time.

Teams A and B found the framework and its terminology to be equally understandable. However, the responses of team A averaged between 0.5 and 1.5 points lower than those of team B; a differential which was also apparent in the responses to the team 
performance questionnaire. This finding appears to suggest that there is a connection between the manner in which the framework is utilised and individual perception of team performance.

\begin{tabular}{|l|}
\hline The framework and its terminology were clearly understandable to me \\
\hline The design framework helped me personally to work within the team. \\
\hline The design framework helped us to be more effective as a team \\
at the appropriate time
\end{tabular}

Figure 6 Design framework questionnaire responses by team

\section{Analysis of data}

\subsection{Activity and phase duration}

Table 1 provides a breakdown of the percentage of time spent by the teams on each of the activities and phases (represented graphically in figure 7).

There is little consistency in the time spent on each of the activities (average co-efficient of variation $=42 \%)$. However, there was significantly less variability in the time spent on each phase (average co-efficient of variation $=15 \%$ ), particularly during phase 1 (Interpret: 2\%) and phase 3 (divergence: 8\%). However, it is unclear without further 
investigation whether this correlation has any significance in improving understanding of conceptual design activity.

\begin{tabular}{|c|c|c|c|c|c|c|c|c|}
\hline & & & \multicolumn{6}{|c|}{$\begin{array}{l}\% \text { of design time spent in section of the } \\
\text { framework }\end{array}$} \\
\hline Phase & \multicolumn{2}{|r|}{ Activity } & \multicolumn{2}{|c|}{ Team (A) } & \multicolumn{2}{|c|}{ Team (B) } & \multicolumn{2}{|c|}{ Team (C) } \\
\hline \multirow{3}{*}{ Interpret } & 1 & Specify the need & 6 & \multirow{3}{*}{21} & 7 & \multirow{3}{*}{22} & 9 & \multirow{3}{*}{21} \\
\hline & 2 & Assess functional requirements & 7 & & 11 & & 6 & \\
\hline & 3 & Identify essential problems & 8 & & 4 & & 6 & \\
\hline \multirow{3}{*}{ Develop } & 4 & Develop functional requirements & 11 & \multirow{3}{*}{21} & 8 & \multirow{3}{*}{14} & 2 & \multirow{3}{*}{10} \\
\hline & 5 & Set key requirements & 8 & & 2 & & 6 & \\
\hline & 6 & Determine project characteristics & 2 & & 4 & & 2 & \\
\hline Diverge & 7 & Search for solution principles & 22 & 22 & 18 & 18 & 20 & 20 \\
\hline \multirow{3}{*}{ Transform } & 8 & Transform and combine solution principles & 3 & \multirow{3}{*}{5} & 14 & \multirow{3}{*}{32} & 14 & \multirow{3}{*}{16} \\
\hline & 9 & Select suitable combinations & 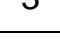 & & 14 & & 14 & \\
\hline & 10 & Firm up into concept variants & 2 & & 18 & & 2 & \\
\hline \multirow{2}{*}{ Converge } & 11 & Evaluation and choice of alternatives & 10 & 10 & 4 & 4 & 16 & 16 \\
\hline & 12 & Improve details & \multicolumn{6}{|c|}{ Not included in comparison } \\
\hline \multicolumn{3}{|c|}{ Time unclassified by phases of model } & \multicolumn{2}{|c|}{21} & \multicolumn{2}{|c|}{10} & \multicolumn{2}{|c|}{17} \\
\hline \multicolumn{3}{|c|}{ Total spent in phases 1-6 } & \multicolumn{2}{|c|}{42} & \multicolumn{2}{|c|}{36} & \multicolumn{2}{|c|}{31} \\
\hline \multicolumn{3}{|c|}{ Total spent in phases $7-12$} & \multicolumn{2}{|c|}{37} & \multicolumn{2}{|c|}{54} & \multicolumn{2}{|c|}{52} \\
\hline
\end{tabular}

Table 1 Percentages of time spent on each design activity and phase

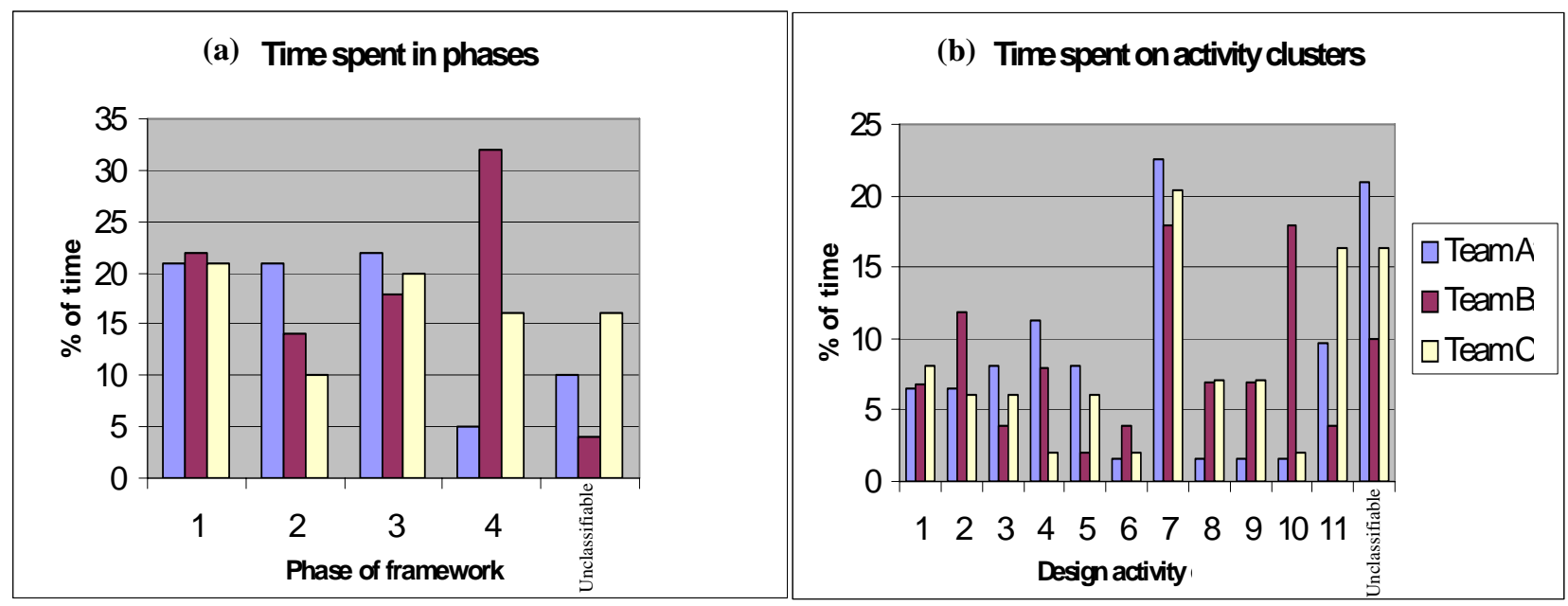

Figure 7

Graphical comparisons of team effort 


\subsection{Unclassifiable activity}

As can be seen from table 1, between $10 \%$ and $21 \%$ of the time spent designing could not be classified within the preliminary conceptual design framework model. This time was spent on a number of activities:

- Introductions by team members.

- Individuals outlining their roles within the design team.

- The pooling of knowledge - team members giving a synopsis of their knowledge of window system design and precedent cases.

- Planning and discussing the process of design to be followed.

- The development of a shared understanding of the requirements of the system.

- The generation of programmes to allocate time periods to particular activities.

- Identifying interconnected and unconnected elements of the design problem and solution.

- Discussion of problems regarding the performance of the team

Upon further analysis of this final point it became apparent that discussions were generally based on five specific issues:

- Working as a team (initial introductions, roles, responsibilities: defining teamwork)

- Maintaining interaction between members

- Lack of communication

- Team dynamics (attempts to maintain collaboration between team members) 
- $\quad$ Redirecting the team to maintain efficiency

To this end, it was recognised that one of the main elements missing from the design framework is the need to recognise and manage team maintenance. This needs to be addressed and accounted for in a realistic model of conceptual design activity.

\subsection{Dependency across activities}

The patterns of actual design progression of the teams through the framework activities (figures 2-4) could be the result of one of two things: i) there is some form of dependency between those activities; or ii) the team picked the next activity to be addressed at random, simply because they recognised that it had to be visited at some point during the

process. However, if the latter eventually proves to be true then present attempts to understand conceptual design are doomed to fail. For the purposes of this research it has been assumed that design progression has an underlying rationale, and it is this that the authors seek to discover and, ultimately, support.

A technique developed in the 1980's ${ }^{21}$ known as the dependency structure matrix (DSM), which has been applied previously in design research 22, 23, 24, 25 to portray the dependencies between sets of activities, can be utilised to analyse design progression. In the context of this investigation, the DSM is produced by assuming that, as the various patterns of progression depict the actual design activity of the teams, progression from one activity to another must be the result of some dependency between those activities. The DSM works on the premise that the activities are undertaken in the order suggested 
by the rows (and columns; which are always in the same order). The dependence of one activity (e.g 2) on another (e.g 4) is indicated by placing a mark in row 2, column 4 of the matrix. A mark placed above the diagonal indicates feedback (i.e dependence on a future activity) and hence, iteration.

A DSM is usually evolved from a previously defined process model of activities and dependencies. The optimum order of activities (minimising iteration) can be found by applying a 'partitioning' algorithm. In this instance the process has been reversed: the sequence in the pattern of progression has been used to infer the activity dependencies and hence, construct the matrix.

Once the DSM has been produced it can be used to identify 'loops' of activities based on the boundary of those marks which appear above the leading diagonal (the shaded areas), where iteration occurred between several activities. DSMs representing each team's design progression are shown in Figures 8, 9 and 10.

\section{Team A}

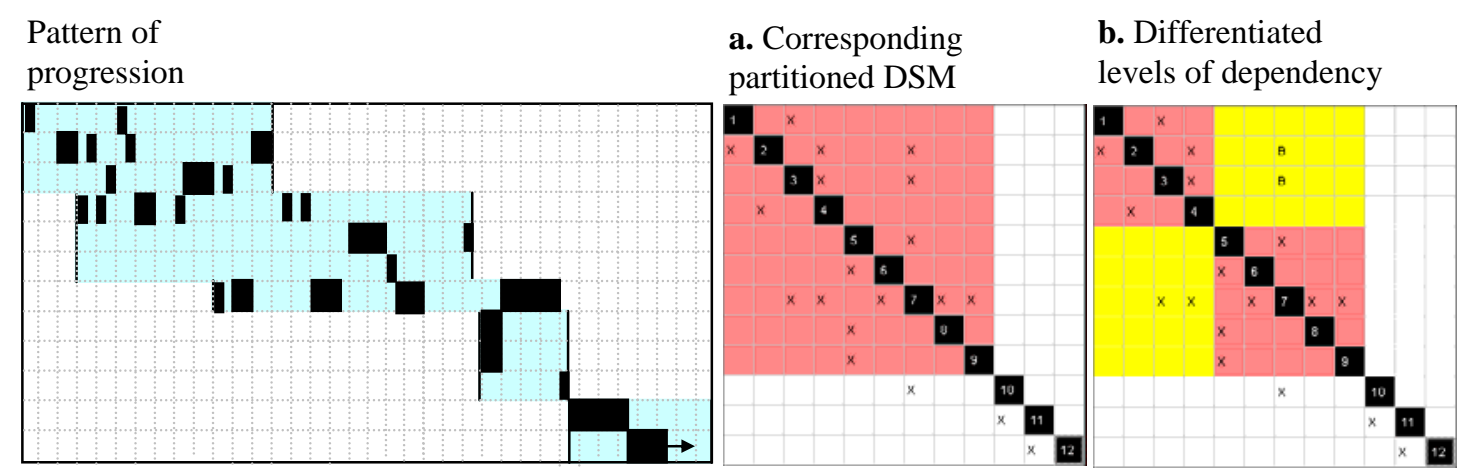

Figure 8 DSMs representing design progression of team A 
The DSM of team A (figure 8-a) portrays a large interdependency block within and between activities 1-9. During this period, rather than completing one activity entirely before progressing to the next, the team jumped between them. Once they had selected suitable combinations of concepts (activity 9) they progressed sequentially through the remainder of the design activity.

However, within the large iterative block of activities a differentiation can be drawn between the nature of dependencies. If those marks furthest from the leading diagonal are designated as having a different level of dependency (marked B) to those representing a lesser backward step (i.e. those falling closer to the leading diagonal) it is apparent that iterations within certain clusters of activities fall inside the higher level of iteration represented by the large dependency block. This revised DSM (figure 8-b) moves closer to the DSM describing team B's design activity (figure 9).

\section{Team B}

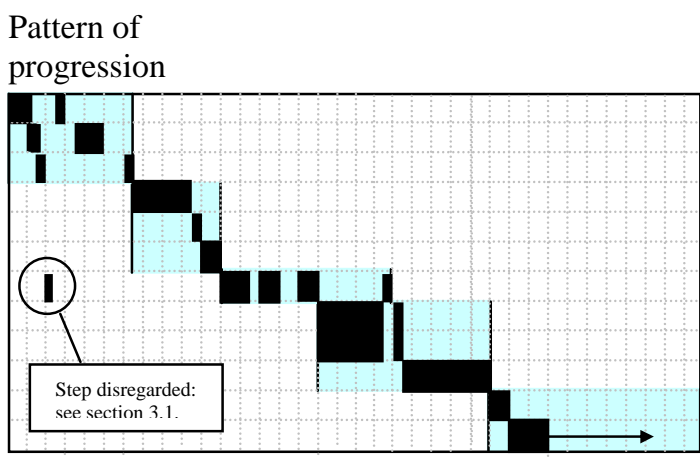

Corresponding partitioned DSM

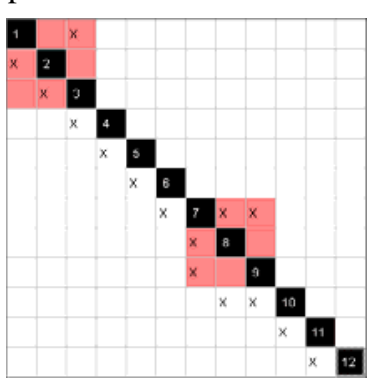

Figure 9 DSM representing design progression of team B 
The design progression of team B is very similar to that of team A (figure 8-a), with each describing two blocks of interdependence. However, they differ in the fact that the blocks of iteration described in figure 9 are independent of one another and are not contained within a larger iterative loop. Activities 1-3 are interdependent, after which there is a sequential progression up to the determination of project characteristics (activity 6). Upon completion of this activity, the following three activities - 7) searching for solution principles; 8) transforming and combining these, and 9) selecting suitable combinations, were undertaken in an iterative manner. Again, once this 'loop' was complete the remaining design activity was undertaken sequentially.

\section{Team C}

Like team A (figure 8-a), the DSM developed from team C (figure 10-a) portrays a single large block of interdependency. However, the interdependency lies within and across activities 3-12, rather than activities 1-9. The team progressed sequentially through the first 2 activities before entering this large iterative loop. If, as with team A's DSM, marks furthest from the leading diagonal are represented differently to those near to it, two independent clusters of interdependent activities lay within the larger iterative block.

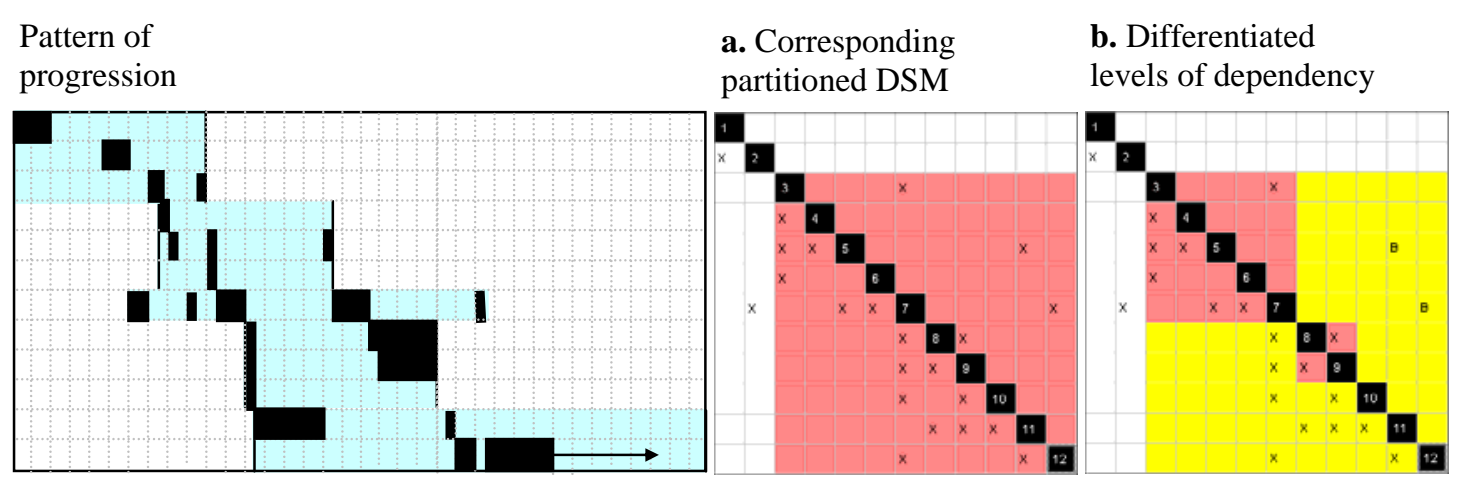

Figure 10 DSMs representing design progression of team C 
However, it is important to note that, once the team had identified the essential problems (at activity 3), they undertook what appear to be two similar processes to complete the exercise. Upon further examination it is apparent that, if the two similar processes are considered separately, the design progression, and the resulting DSMs, are very similar to those exhibited by team B.

\subsection{Duration and nature of phase interdependency}

The DSMs in figures 8, 9 and 10 describe the varying degrees of interdependency between the 12 activities as undertaken by the workshop teams. However, considering the manner in which the five, second level, phases were undertaken provides further insights into the nature of conceptual design activity (Table 2).

\begin{tabular}{|c|c|c|c|c|c|c|}
\hline & \multirow{2}{*}{ Team } & \multirow{2}{*}{$\begin{array}{l}\text { Addressing a } \\
\text { single phase } \\
\text { only }\end{array}$} & \multicolumn{3}{|c|}{ No. of phases addressed in parallel } & \multirow{2}{*}{$\begin{array}{c}\text { Total design } \\
\text { time up to } \\
\text { activity } 12 \\
\text { final step } \\
\end{array}$} \\
\hline & & & 2 & 3 & 4 & \\
\hline \multirow{3}{*}{ 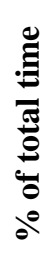 } & A & $20 \%$ & $57 \%$ & $23 \%$ & N/A & $305 \min$ \\
\hline & B & $84 \%$ & $16 \%$ & N/A & N/A & $250 \min$ \\
\hline & C & $24 \%$ & $39 \%$ & $20 \%$ & $16 \%$ & $245 \min$ \\
\hline
\end{tabular}

Table 2 Nature of design activity by phase interdependency and duration

Team B spent the majority of their design time working through the phases in series, first completing one phase before commencing the next, and only a small proportion (approximately 16\%) in parallel. This iterative behaviour represented divergent search for concepts and their ensuing transformation. This sequential progression is the direct result of following the experimental procedure. 
The more important observation relates to the manner in which teams A and C progressed with respect to addressing phases in parallel (Table 2). Team A, which had a copy of the framework to utilise as a guiding principle, addressed two phases in parallel for the majority of the time (57\%), followed by three phases for $23 \%$, and a single phase for only 20\%. At no point during the exercise did they attempt to address four phases in parallel.

Team C however, which had no framework, although spending a similar proportion of time undertaking more than one phase, spent approximately $16 \%$ of their design time considering four phases simultaneously.

Team C spent much longer than team A 'Interpreting the need' in isolation of the other phases, before attempting to address other issues simultaneously. After this point team A addressed only 3 , or less, phases in parallel for the remainder of the exercise. Team $\mathrm{C}$ however, mid-way through their design activity, spent 40 minutes (approximately 16\% of their overall design time) addressing 4 phases in parallel.

\begin{tabular}{|c|c|c|c|c|c|c|}
\hline & \multirow{2}{*}{ Iteration } & \multirow{2}{*}{$\begin{array}{c}\text { Addressing } \\
\text { a single } \\
\text { phase only }\end{array}$} & \multicolumn{3}{|c|}{ No. of phases addressed in parallel } & \multirow{2}{*}{$\begin{array}{c}\text { Total desigr } \\
\text { time up to } \\
\text { activity } 12 \\
\text { final step } \\
\end{array}$} \\
\hline & & & 2 & 3 & 4 & \\
\hline \multirow{2}{*}{ 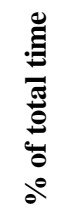 } & First & $64 \%$ & $19 \%$ & $16 \%$ & N/A & $160 \mathrm{~min}$ \\
\hline & Second & $66 \%$ & $34 \%$ & N/A & N/A & $160 \mathrm{~min}$ \\
\hline
\end{tabular}

Table 3 Analysis of two individual iterations performed by team C 
It must be remembered that team C's progression through the activities, once activity four had been completed, represented two discrete iterations (figure 4). Table 3 considers these two progression patterns individually, based on the premise that phase one is common to both iterations.

This data suggests that a larger proportion of time, approximately $65 \%$, was spent undertaking phases in isolation of one another. Additionally, rather than considering 4 phases in unison for periods during the design activity, team $\mathrm{C}$ actually considered 3 phases in parallel during the first iteration and then only two during the second. This implies that team $\mathrm{C}$, who were considered to have developed the solution which could be subsequently developed to meet the brief most effectively, considered phases in isolation, and two and three phases in parallel to generate the holistic concept. After which, the team, having settled on the high level concept, developed the final proposal by undertaking phases singularly, or by considering no more than two phases in parallel. This suggests that team $\mathrm{C}$ considered multiple phases to form the concept, which then allowed them to reduce the number of phases being performed in unison to crystallise the proposal.

\subsection{Observations and comparison}

Considering figures 8, 9 and 10 in addition to the analysis undertaken in section 4.4, it is apparent that iterations across the activities and phases of the recorded design processes fit within a higher level of iteration representing the entire conceptual design phase. In 
light of these findings the preliminary design framework has been developed into a more realistic representation of the conceptual design phase (figure 11).

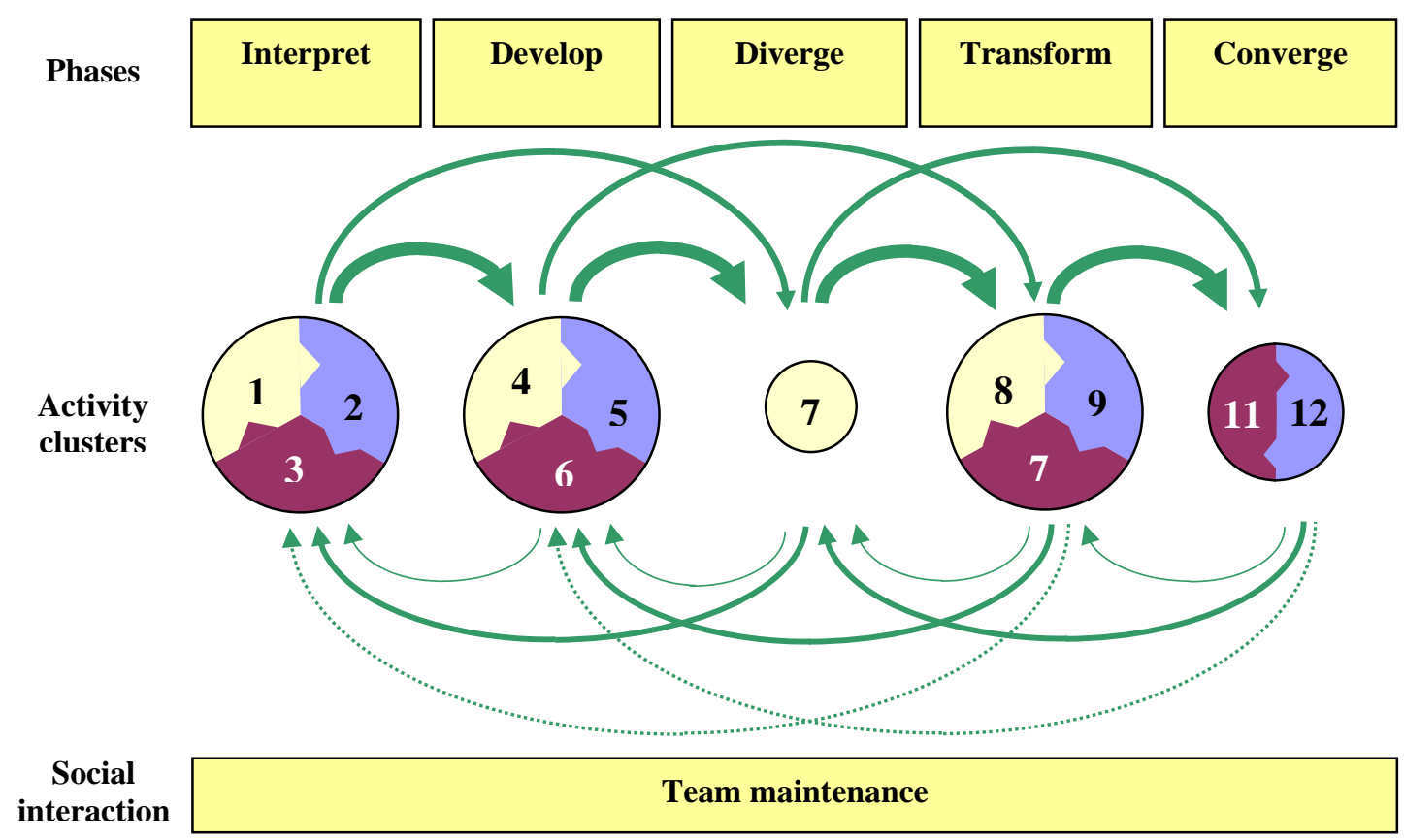

Figure 11 Reinterpreted conceptual design framework model

In the DSMs that were produced from the team design activity (figures 8, 9 and 10), interdependencies between the majority of activities within the framework were common However, by designating different levels of dependency within these iterative blocks, it has been shown that there are also dependencies within specific clusters of activities (activities clustered by phase within figure 11). The arrows designate these connections, with the frequency of occurrence being indicated by line thickness. 
This concept of iteration-within-iteration has been proposed previously by Hickling ${ }^{26}$, who represented the whirling process of decision making in design in a similar manner (figure 12).

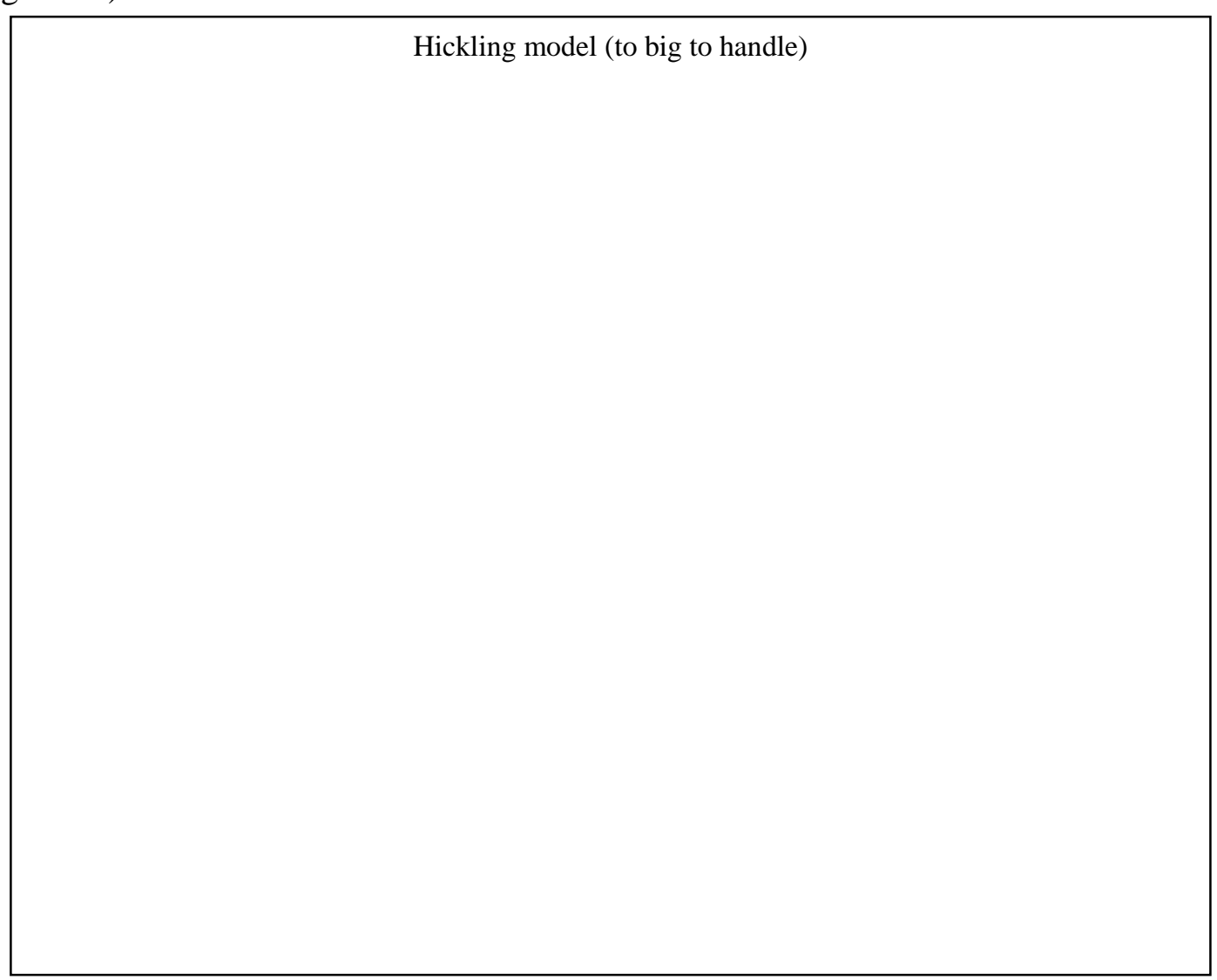

Figure 12 The extended whirling process

Owing to the fact that 'no foolproof experiment was available with which to demonstrate these connections’ ${ }^{26}$, Hickling suggested, rather than asserted, their existence. However, upon comparing the iterative nature of the design activity of the workshop teams with the cyclic whirling process prescribed by Hickling, the notion that differing levels of dependency exist within and across activities appears to be substantiated. 


\section{$5 \quad$ Summary and conclusions}

This research involved three interdisciplinary design teams made up of a number of design professionals from several different organisations. The investigations did not take into account the abilities, expertise or knowledge base of the individual designers and as such, no comment can be passed on the influence that these issues can have on the design process. In statistical terms the number of participants in the workshop is very few and it would be premature to draw general inferences from this limited evidence. However, within these limitations, the following conclusions were drawn:

i. the majority of design activity undertaken by the teams (between 79 and 90\%) could be classified within the activities of the conceptual design framework;

ii. social interaction and team maintenance account for a portion (between 10 and 21\%) of design time but neither issue is classified within the conceptual framework model;

iii. the evidence suggests that designers perceive they have performed better as a team when they agree on, and subsequently follow, a design process;

iv. there is no evidence to suggest that following a design process, be it in an iterative or systematic manner, will help the team to generate a better design concept or reduce the time period spent reaching that concept;

v. the evidence suggests that a team must be led throughout the design activity. However, the team must agree on who should lead it and how it should be led if it is to work effectively as a unit and avoid confrontation; and 
vi. if the team does not agree on a design process to follow, individual team members tend to make opportunistic forays into particular areas of the problem in an ad hoc manner. If other team members do not agree on the direction of that foray then this can lead to a lack of synchronisation in the team effort and a lack of input from one or a number of it's members.

In light of these conclusions it is apparent that initial validation of the framework structure has been achieved. Additionally, this initial validation of the preliminary conceptual design framework has enabled an improved representation of conceptual design activity to be generated which not only describes the activities and phases of conceptual design, but also illustrates their interconnectedness. Moreover, a critical component of conceptual design activity, namely the process of social interaction, which was missing from the preliminary framework, has now been introduced and embedded within the revised model. Future development of the conceptual design framework involves turning it into a web-based design tool intended for use by design teams ${ }^{27}$. At some point in the future the authors hope to report on its acceptability and usefulness in practice.

\section{Acknowledgements}

This work has been undertaken as part of a project entitled 'Mapping the Design Process during the conceptual phase of building projects'. The research is funded under research grant GR/L39292 by the EPSRC and industry (AMEC Design, BAA Plc., Hotchkiss Ductwork Ltd, Hutter, Jennings and Titchmarsh, Matthew Hall, and Pascall \& Watson). 
Loughborough University is also contributing to the project. The final version of the paper benefited from suggestions made by the referee.

\section{References:}

1. Markus TA (1969). 'The role of building performance measurement and appraisal in design method'. In Broadbent, Ward (eds.) Design methods in Architecture. London, Lund Humphries.

2. Maver TW (1970). 'Appraisal in the building design process'. In Moore GT (ed.). Emerging methods in environmental design and planning. Cambridge, Mass. MIT Press.

3. French M.J (1971). Engineering Design: The Conceptual Stage. Heinemann Educational Books.

4. Archer B.L (1984). 'Systematic method for designers'. In: Cross, N (ed.) Developments in design methodology. Wiley, Chichester, UK, pp. 57-82.

5. Pugh S, Morley IE (1988). Total design: Towards a theory of total design. Published by Design Division, University of Strathclyde, UK.

6. Pahl G, Beitz W (1988). Engineering Design: A Systematic Approach. The Design Council-Springer/Verlag.

7. Cross $N$ (1989). Engineering Design Methods: Strategies for Product Design. John Wiley \& Sons.

8. Austin S, Baldwin A, Li B, Waskett P (1999a). 'Analytical design planning technique: a model of the detailed building design process'. Design studies, Vol.20, No3, pp 279-296.

9. Austin S, Baldwin A, Li B \& Waskett P (1999b). 'Analytical Design Planning Technique for Programming the Building Design Process'. Proceedings of the Institution of Civil Engineers, Structures and Building, Vol.134, No.2, May, pp 111-118.

10. BAA Plc (1995). The Project Process: A guide to the BAA project process. Internal publication. BAA Plc, Aug '95. London.

11. Kagioglou et al (1998). A generic guide to the Design and Construction Process Protocol. The University of Salford. 
12. RIBA (1969). Plan of work for Design Team Operation - Royal Institute of British Architects. Original Edition.

13. Minneman S.L (1991). The social construction of a technical reality: Empirical studies of group engineering design practice. PhD Dissertation. Stanford University, USA.

14. Hales, C (1987). Analysis of the engineering design process in an industrial context. PhD Thesis. Cambridge University Press.

15. Blessing LTM (1996). A process based approach to computer supported engineering design. Black Bear Press Ltd, Cambridge, UK.

16. Hubka V (1982). Principles of engineering Design. Butterworths \& Co.

17. Macmillan S, Steele J, Austin S, Spence R, Kirby P (1999a). 'Mapping the early stages of the design process - a comparison between engineering and construction'. Proceedings of $12^{\text {th }}$ International Conference on Engineering Design (ICED '99). Munich, Germany.

18. Austin S, Steele J, Macmillan S, Kirby P, Spence R (1999). 'Using training workshops to map interdisciplinary team working'. Proceedings of Chartered Institute of Building Services Engineers National Conference 1999, Harrogate, UK.

19. Macmillan S, Steele J, Austin S, Spence R, Kirby P (1999b). 'Development of a generic conceptual design framework’. Submitted to Design studies for publication.

20. Macmillan S, Steele J, Austin S, Spence R, Kirby P (1999c). 'Testing design tools in an interdisciplinary design environment'. Working paper. The martin centre, University of Cambridge, UK.

21. Steward, D (1981). Analysis and management: structure, strategy and design. Petrocelli Books, Princeton, NJ, USA.

22. McCord K, Eppinger S (1993). 'Managing the integration problem in concurrent engineering’. Working paper. MIT Sloan School of Management, WP 3594-93 1993.

23. Rogers J, Padula S (1989). An intelligent advisor for the design manager. NASA Technical Report, TM-101558.

24. Huovila P, Koskela L, Lautanala M, Tanhuanpaa V (1995). 'Use of the design structure matrix in construction.' Proceedings of $3^{\text {rd }}$ International workshop on lean construction, Albuquerque. 
25. Austin S, Baldwin A, Li B, Waskett $P$ (1998). 'Development of the ADePT methodology: an interim report on the Link IDAC 100 Project'. Department of Civil and Building Engineering, Loughborough University, UK.

26. Hickling A (1982). 'Beyond a linear iterative process?' In Evans B, Powell JA, Talbot RJ (eds.) (1982) Changing Design. John Wiley and Sons Ltd. UK.

27. Steele J, Austin S, Macmillan S, Kirby P, Spence R (forthcoming). 'An internetbased system to support interdisciplinary and inter-organisational collaborative conceptual design'. Chartered Institute of Building Services Engineers (CIBSE) National Conference, Dublin, UK. 